\title{
Who is being deceived? The experimental demands of wearing a backpack
}

\author{
Frank H. Durgin, Jodie A. Baird, Mark Greenburg, \\ Robert Russell, Kevin Shaughnessy, and Scott Waymouth \\ Swarthmore College, Swarthmore, Pennsylvania
}

\begin{abstract}
A growing literature argues that wearing a heavy backpack makes slopes look steeper and distances seem longer (e.g., Proffitt, 2006). To test for effects of experimental demand characteristics in a backpack experiment, we manipulated the experimental demand of the backpack and then used a postexperiment questionnaire to assess participants' beliefs about the purpose of the backpack. For participants in the low-demand condition, an elaborate deception was used to provide an alternative explanation of the requirement to wear a heavy backpack (i.e., that it held EMG equipment). The highest slope judgments were found for those undeceived participants who guessed that the backpack was intended to affect their slope perception and also reported that they thought they were affected by it. When persuaded that the backpack served another purpose, participants' slope estimates were no different from those of participants not wearing a backpack. These findings suggest that backpack effects, and other reported effects of effort on perception, are judgmental biases that result from the social, not physical, demands of the experimental context.
\end{abstract}

Psychologists have long known that research participants are engaged in a social context that encourages compliance (Orne, 1962). For this reason, we are often more convinced by experiments that involve implicit measures or successful deceptions. Proffitt (2006) and colleagues have argued that the perception of spatial layout, such as distance and surface orientation, is strongly affected by physiological and contextual factors relevant to action. They report, for example, that wearing a heavy backpack directly influences slope perception (Bhalla \& Proffitt, 1999). The alternative hypothesis, that experimental demands of the situation encourage participants to elevate their cognitive estimates of slope, has never been directly tested. Although backpack studies represent only one manipulation among many convergent measures used to argue that perceived slope depends on behavioral potential (Proffitt, 2006), we know that the interpretation of apparently convergent tests of a hypothesis may be guided by confirmation bias (Wason, 1960), and thus each individual piece of evidence deserves careful scrutiny. Here we test the alternative hypothesis that elevated judgments in backpack experiments are due to experimental demands rather than the physical burden of the backpack.

In most backpack experiments, the hypothesis appears fairly transparent. For example, Bhalla and Proffitt (1999) reported that hills appeared steeper when participants were required to wear a heavy backpack. The only justification given to participants for the backpack was that its weight also had to be estimated. Proffitt, Stefanucci, Banton, and Epstein (2003) later reported that heavy backpacks made distances seem longer. No cover story for the backpack was reported. In both these studies, the apparent effects on perception were found using explicit judgments of slope or distance, but were interpreted as true perceptual effects, rather than as possible biases in judgment.

It remains possible that the experimenters' hypotheses in these studies were transparent to participants and that the reported response differences reflect biases in judgment in compliance with experimental demand characteristics. It is not trivial to distinguish perception from judgment, but it is not necessary to conclude that all effects on perceptual judgments are due to real changes in perceptual experience. Crucially, if it could be shown that a physical burden affected perceptual judgments in a situation where experimental demands were eliminated, the standard interpretation of these effects would be bolstered. Conversely, if manipulating experimental demand characteristics produces changes in judgment similar in magnitude to those previously attributed to backpacks, this would undermine the argument presented by Proffitt (e.g., 2006) that the physical burden of the backpack affects perception directly.

To determine whether the experimental demand of the backpack is transparent, we administered a survey describing an "experiment" (only the backpack condition was mentioned) in which participants wore a heavy backpack while making distance judgments (Russell \& Durgin, 2008). When asked to guess the experimental hypothesis, the majority of respondents suggested that the experimenter hoped to show that distances would look longer when participants wore the backpack. Evidently, the experimental demand is transparent even to those who have not participated in such a task.

F. H. Durgin, fdurgin1@swarthmore.edu 
Here we address the question of whether judgments of slope are affected by participants' awareness of and compliance with the social (rather than physical) demand of wearing a heavy backpack in an experimental context. To investigate, we devised a complicated deception to avoid placing an experimental demand on participants that would encourage them to elevate their slope estimates. In addition, we administered a postexperiment survey that served to assess the effectiveness of the deception as well as the beliefs of participants who were in a more typical backpack manipulation. Our reasoning was as follows: If participants' judgments of slope were primarily affected by the physical burden of wearing a heavy backpack, evidence of elevated estimates of slope ought to be present, even if our deception was successful. Conversely, if the reported effects in prior studies were due to demand characteristics, participants' beliefs about the experiment should primarily determine the results of the backpack manipulation in the present case.

\section{METHOD}

\section{Participants}

Forty-five Swarthmore College undergraduates participated for course credit. All were initially naive to the purpose of the experiment.

\section{Stimuli and Procedure}

Participants were pseudorandomly assigned to one of three conditions. In the no-weight condition $(n=12)$, participants made judgments of slope without a backpack. Participants in each of the two critical conditions were required to wear a heavy backpack $(11.3 \mathrm{~kg} / 25 \mathrm{lbs})$. In the standard backpack condition $(n=13)$, no explanation for the backpack was provided. In the electrode backpack condition $(n=20)$, participants consented to having their ankle muscles monitored by electromyographic (EMG) equipment and to carrying the monitoring equipment in a backpack. Real electrodes were then attached to their ankles with leads that ran into the backpack. To enhance the illusion that the backpack contained working equipment, an electric fan inside the backpack emitted noise, and additional equipment was on display in the lab (including electrode gel, extra leads, and large batteries in the process of being charged). A survey conducted at the conclusion of each backpack session assessed participants' beliefs about the purpose of the backpack and the effectiveness of the intended deception. A higher proportion of participants were assigned to the electrode condition in an attempt to ensure that an adequate number of them remained naive.

The slope stimulus itself was a sturdy wooden ramp $(1 \mathrm{~m} \times 2 \mathrm{~m})$ mounted on cement steps in a remote part of the psychology building. The actual slope of the ramp was $14.5^{\circ}$. Participants were instructed in a main lab room, then (wearing a backpack if appropriate) taken to the top floor of the building by elevator. They were blindfolded for the short walk to the ramp, where the blindfold was removed. A small sticker in the middle of the ramp served as a fixation mark for gaze. Each participant first gave a verbal estimate of the ramp's slope in degrees and then was asked to step onto the ramp and estimate its slope a second time. Prior research in our laboratory has shown that a ramp of this slope feels (when stood upon) even steeper than it looks (Hajnal \& Durgin, 2008).

After their second judgment, participants were escorted back to the laboratory and the backpack (if present) was removed. Participants in both backpack conditions then sat alone at a computer and completed a brief survey. In the standard backpack version, participants were asked to estimate the backpack's weight, rate its comfort, and explain why they thought they were wearing it. A final question asked if they thought their slope judgments had been affected by the weight of the backpack. The electrode version of the survey asked the same questions, except that prior to the final question, participants were asked if they believed that the equipment in the backpack was really recording data. If they answered no, a further question asked what they thought the electrodes were for. These questions were designed to identify those who had been skeptical of the deception ( $25 \%$ were).

\section{RESULTS}

If a physical burden, such as a heavy backpack, is sufficient to alter slope perception, it ought to do so even if participants believe that the backpack is an incidental part of the experimental apparatus. Conversely, if altered judgments of slope in backpack experiments are due to demand characteristics, they ought to be found only among those who might be aware of the intent of the manipulation and who implicitly or explicitly comply with that demand.

\section{The Role of Effort}

Of the 20 participants in the electrode condition, 15 indicated that they believed that the purpose of the backpack was to carry muscle-monitoring equipment (4 of the other 5 suspected that the backpack was intended to alter their slope perception, and the 5th indicated generalized skepticism regarding the study). The average slope judgments of the 15 who apparently remained naive were essentially identical to those of the 12 participants in the no-weight condition (see Figure 1). Although we do not seek to confirm the null hypothesis, there is no suggestion that the weight of the backpack affected their perception of slope, even when they were standing on the slope.

\section{The Role of Belief}

As expected, for those in the standard backpack condition, the experimental hypothesis was obvious. Of the 13 participants in the standard backpack condition, 12 clearly articulated the belief that the backpack was intended to alter their slope perception. Five of these 12 further indicated that they thought the backpack had indeed affected their judgments. Consistent with the idea that backpack effects are due to compliance with experimental demand, average haptic slope judgments of these 5 participants $\left(51^{\circ}\right)$ were reliably higher than those of the 7 who did not think they were affected $\left(27^{\circ}\right)$ $[t(11)=2.42, p=.034, d=1.19]$. Initial visual judgments of slope were also numerically higher for these $5\left(34^{\circ}\right)$ than for the other $7\left(23^{\circ}\right)[t(11)=1.69$, n.s., $d=0.92]$. Two participants in the standard condition who articulated the hypothesis but said that they were unaffected by it were apparently anticompliant: They gave extremely low visual slope estimates $\left(7^{\circ}\right)-4$ standard deviations below the mean of the others in that condition. Even when these 2 outliers were excluded, haptic slope judgments were marginally greater for the 5 who expressed compliance $\left(51^{\circ}\right)$ than for the remaining 5 who $\operatorname{did} \operatorname{not}\left(34^{\circ}\right)[t(9)=2.03, p=.073, d=1.00]$.

\section{The Role of Demand}

To test for effects of experimental demand while controlling for physical effects of wearing the backpack, we compared the judgments of the 15 participants who remained naive in the electrode condition with 11 of the 13 participants in the standard condition (including the 1 participant who did not explicitly articulate the hypothesis); these data are shown in Figure 1. We excluded only the 5 participants 
- No backpack $(n=12)$

$\square$ Electrode condition (naive to hypothesis; $n=15$ )

$\square$ Standard condition (excluding outliers; $n=11$ )

$\square$ Standard condition (believe affected; $n=5$ )

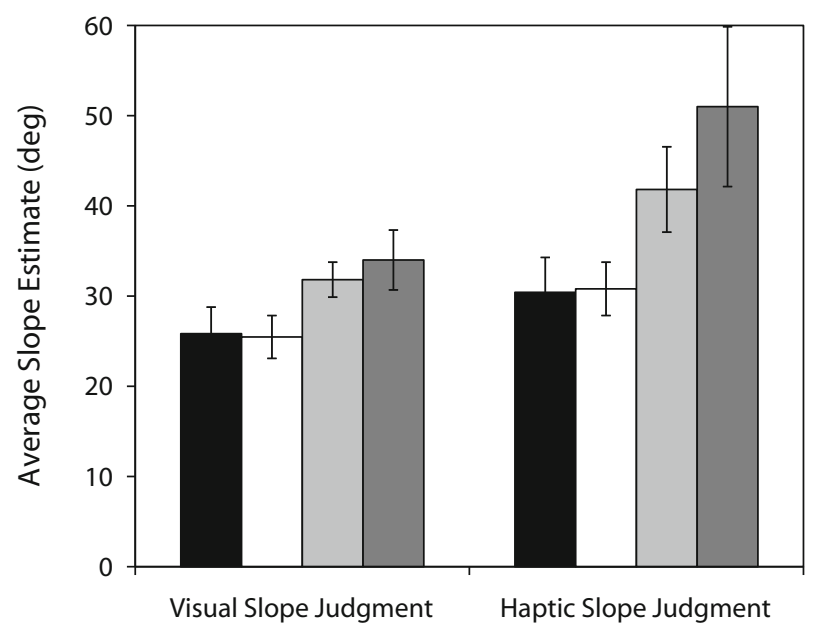

Figure 1. Average slope estimates based on visual inspection of a $14.5^{\circ}$ ramp (left) and haptic perception via standing on a $14.5^{\circ}$ ramp (right), are shown as a function of experimental condition. Data are shown for the 12 participants in the no-backpack control condition (black), the 15 participants in the deception condition who remained naive to the deception (white), and the 11 participants in the standard backpack condition, excluding only 2 outliers (light gray). The 5 participants in the standard backpack condition who later indicated that they thought the weight of the backpack had affected their judgments are broken out into a separate bar (dark gray), but are also included within the standard condition data. Error bars represent standard errors of the means.

in the electrode condition who were skeptical of the deception and the 2 outliers in the standard condition. An ANOVA with demand (electrode, standard) as a between-subjects measure and judgment type (visual, haptic) as a withinsubjects measure confirmed that the standard backpack condition led to larger estimates of slope $[F(1,24)=4.98$, $\left.p=.035, \eta^{2}=.21\right]$. Hierarchical linear analysis also indicated that a model including demand as a factor explained reliably more variance $\left[\chi^{2}(1)=4.89, p=.027\right]$. The model estimate of the effect was $7.6^{\circ}\left(95 \% \mathrm{CI}: 0.8^{\circ}-16.4^{\circ}\right)$. This is comparable to the $4^{\circ}$ effect reported by Bhalla and Proffitt (1999) for judgments of visual slope. Both analyses also indicated that haptic judgments were higher than visual ones $\left[F(1,24)=12.80, p=.001, \eta^{2}=.51, \chi^{2}(1)=10.78, p=\right.$ $.001]$, but neither analysis detected a reliable interaction between demand and judgment type.

\section{Memory Bias}

Although not predicted, estimates of backpack weight from memory also differed by demand. The average weight estimate of the 11 analyzed participants in the standard condition (30 lbs) was higher than the average estimate given by the 15 analyzed participants in the electrode condition (19 lbs) $[t(25)=2.74, p=.011, d=0.97]$. Because the backpack was described as "heavy" in the consent form for the standard condition, this could be a verbal misinformation effect on memory (Loftus, Miller, \& Burns, 1978; Loftus \& Palmer, 1974).

\section{Anchoring and Correlation}

Could it nonetheless be argued by effort theorists that the effect of the backpack on slope perception was mediated by its perceived (i.e., remembered) rather than physical weight? This would undercut the functional utility of effort theory. Moreover, correlations between dependent measures can be due to artifacts of judgment as well. For example, anchoring theory (Tversky \& Kahneman, 1974) predicts that numeric judgments under uncertainty (like remembered backpack weight) will be affected by prior, irrelevant numbers (like slope estimates), and among the 15 analyzed participants in the electrode condition there was a positive correlation between haptic slope estimates and estimates of backpack weight $(r=.50, p=.057$, onetailed). The presence of this correlation within the group of participants whose mean slope estimates were indistinguishable from those of the unburdened controls suggests that the correlation is due to anchoring, not effort.

In contrast, there is no support for the hypothesis that slope judgments in the high-demand standard condition were mediated by perceived weight. Within the group that actually gave elevated slope estimates overall (the 11 nonoutliers in the standard group), and whose slope estimates were shown above to differ by expressed compliance with demand, there was no reliable correlation between the judgments of backpack weight and the visually based judgments $(r=.04)$ or haptically based judgments $(r=-.05)$ of the slope. Even the two outliers in the backpack condition who gave particularly low slope estimates gave typical weight estimates of the backpack itself ( $29 \mathrm{lbs})$. This is consistent with the idea that it was not perceived weight but compliance with perceived demand that elevated the slope estimates of the standard backpack condition.

\section{DISCUSSION}

Verbal estimates of physical magnitudes like slopes, distances, and even backpack weight represent judgments based not only on perceptual information or memory, but also on other cognitive factors, including social context. In an effort to discriminate between perceptual effects and effects that are postperceptual, we sought to manipulate the likelihood that our participants would conclude that the backpack was intended to affect their slope perception. When our deception was successful and participants believed the backpack to contain monitoring equipment rather than believing it to be the primary experimental manipulation, no differences were found between the judgments of those wearing the backpack and those wearing no backpack at all. Thus, at least in our task, there is no evidence for an effect of a heavy backpack on the perception of slope independent of demand characteristics of the experiment. Moreover, judgments of slope were elevated among those for whom the standard experimental hypothesis regarding the backpack seemed transparent, and this elevation was especially evident among those who believed they were affected. Because the presence or absence of a true change in perception should not be available to introspection (the slope should simply seem to be whatever it seems to be), it seems safe to conclude that it 
was judgment rather than perception that was altered for these participants, whom we have labeled compliant. Evidently, the change in slope estimation was caused not by the weight of the backpack itself but by the implicit social demand of being in an experiment in which one is asked to wear a heavy backpack while making estimates of slope.

Our experiment differed in several details from the study conducted by Bhalla and Proffitt (1999), but the most important of these differences is distinctly in our favor: Rather than conducting a controlled experiment, Bhalla and Proffitt administered their backpack manipulation to 40 introductory-psychology students and compared the resulting slope estimates to prior data they had collected from passersby not wearing backpacks. In contrast, our manipulation employed random assignment to conditions and utilized an elaborate experimental control for demand characteristics. We detected an effect similar in magnitude to theirs in the matched (no-deception) backpack condition, but can safely attribute it to experimental demand, because we experimentally manipulated this demand. The fact that our procedures differed from theirs in some details is not telling, because our goal is not to dispute the reproducibility of their result, but to consider an alternative interpretation of the effect they reported.

The pattern of results we have reported here is probably not a result of incidental details of our procedures (e.g., the electrodes). The same pattern of statistically reliable results was found in a preliminary study (Russell \& Durgin, 2008), which tested a similar backpack manipulation on slope perception in virtual reality with 30 participants. No electrodes were used. Instead, the explanation offered for the heavy backpack in the deception condition of that experiment was that it contained part of the video apparatus for the head-mounted display. There, too, we found reliably higher verbal estimates of slope in the standard backpack condition than in the deception condition, but no difference between those in the deception condition and the unburdened controls. A limitation of that experiment was that participants' beliefs about the experiment were not directly assessed. The manipulation of demand characteristics worked, nonetheless. Given that these two different forms of our backpack experiment both suggest that differences in slope estimates were due to demand characteristics, and given that the Bhalla and Proffitt (1999) study did not control for demand characteristics, we think it is reasonable to conclude that there is presently no experimental evidence that heavy backpacks actually affect slope perception.

The fact that perceptual responses can be affected by social demands is well established (e.g., Asch, 1956). Our findings add to the weight of this evidence and are inconsistent with the more controversial claim of Bhalla and Proffitt (1999) that the physical burden in backpack manipulations affects perception by altering behavioral potential. Consistent with our view, Schnall, Harber, Stefanucci, and Proffitt (2008) recently tested the hypothesis that the backpack effect on slope estimation could be ameliorated by the presence or imagined presence of a support person, such as a friend. Although it is not their favored interpretation, the success of their manipulation is readily interpretable in terms of resistance to social demand. For example, Asch (1956) found less compliance with the majority when even a single confederate expressed a minority view. The idea that the effects of implied social pressure (such as experimental demand characteristics) could be ameliorated by social support seems fairly uncontroversial, and now appears to be an alternative explanation of Schnall et al.'s results, though they did not consider it.

The evidence we report suggests that apparent backpack effects may be limited to a subset of compliant participants. This points to an interpretive concern regarding a recent report of an effect of fear on judged slope (Stefanucci, Proffitt, Clore, \& Parekh, 2008). In that study, participants judged the slope of a steep hill that they viewed from the top while standing either on a box (low-fear condition) or on an immobilized skateboard (high-fear condition). Both of these conditions are likely to convey experimental demands to increase slope estimates, but the experimenters used a fear questionnaire to isolate the two experimental groups. Participants reporting too little fear in the skateboard condition were eliminated, as were participants reporting too much fear in the box condition. But eliminating slope judgment data based on differential self-report of fear in the two conditions might have served to sort participants by compliance with experimental demand. Compliant participants should have been more likely to report being fearful and to estimate the slope as steeper. Participants of this sort would have been eliminated from the box condition and retained in the skateboard condition, thus skewing the resulting data in favor of the hypothesis.

Another manipulation susceptible to a related reinterpretation involves the role of intent (Witt, Proffitt, \& Epstein, 2004). In this study, participants' estimates of distance were increased after a manipulation in which they first threw a very heavy ball at a target. Witt et al. reported that the effects on judgments occurred only if participants believed they were about to throw again, and not if they thought another task was to follow. This result seems strange because in prior backpack studies, for example, intent to walk was never present. Although Witt et al. argued that "intent" to throw mediated the "effort" effect produced by the heavy ball, an alternative interpretation suggested by our findings is that such task specificity might be due to compliant participants' beliefs concerning the relevance of the earlier experimental manipulationthrowing the ball- to the job of estimating distance. For compliant participants to cooperate, they must form the correct hypotheses about what is expected of them. Our supposition that the effect on distance estimates of throwing a heavy ball was probably due to experimental demands is supported by a recent study: Woods, Philbeck, and Danoff (2009) have been unable to replicate the reported effect of throwing a heavy ball except in a condition in which the instructions encouraged participants to take nonvisual aspects of the situation into account (see also Hutchison \& Loomis, 2006).

Different interpretive issues arise for other kinds of studies, as well. For example, Balcetis and Dunning (2007) used clever manipulations of perceived choice to induce cognitive dissonance in participants required to do embarrassing or strenuous activities across distances or slopes. 
Subsequent estimates of the distances and slopes traversed differed as a function of perceived choice, consistent with the predictions of cognitive dissonance theory. These results were described as being perceptual consequences of dissonance but were in both cases based on perceptual estimates made from memory. We would emphasize that one of the unanticipated effects of our manipulation (on judgments concerning the weight of the backpack) was, similarly, based on memory. Such effects are clearly not due to effort, and might simply be judgmental distortions in conformance with beliefs.

Could these concerns about compliant participants be alleviated by double-blind experiments? For example, what if proponents of the effort hypothesis used a double-blind manipulation in which high-sugar drinks were shown to reduce estimates of slope? Although double-blind studies help reduce the risk of experimental demands in principle, it is unclear whether double-blind conditions can be maintained with high doses of sugar. In the absence of a deception concerning the nature of the experiment, compliant participants may deduce which condition they are in and act accordingly. Moreover, altered judgments might even result from attribution errors of energized participants (Nisbett \& Wilson, 1977; Schachter \& Singer, 1962), rather than from energy-based alterations in perception.

One problem with the use of converging operations to establish controversial hypotheses is that the use of multiple confirmatory sources of evidence appears particularly susceptible to errors of inference related to confirmation bias (Wason, 1960). As a final example of this risk, we note that Bhalla and Proffitt (1999) reported that hills appeared steeper to the elderly than to college-age participants, and interpreted this in the framework of behavioral potential. We, like most readers, nodded our heads at the time, accepting this as useful evidence in support of the theory. However, Crabtree, Norman, Bartholomew, and Ferrell (2008) have recently found that slant estimates by the elderly are also higher for small surfaces than are those of college-age participants, suggesting that slope overestimation in the elderly applies to a broader range of contexts than those predicted by the effort hypothesis and may require a different form of explanation. Our present findings do not falsify the general hypothesis that slope perception is related to behavioral potential, but they do call into question some of the evidence presently taken to support the theory.

It is problematic to interpret differences in estimates concerning physical quantities as differences in perceptual experience (Granrud, 2009). This is not to argue in all cases against the utility of verbal measures, but only to emphasize that they must be interpreted with caution because they may include judgmental biases. Research on the effects of backpacks, intent, fear, and other nonvisual factors on judgments of slope and distance should actively consider alternative accounts in terms of misattributions (Nisbett \& Wilson, 1977) and judgmental biases (Tversky \& Kahneman, 1974). This means the methods of social psychology will need to be applied more critically. The nuance of social interaction in psychology experiments means that we may sometimes have to deceive our participants or risk being inadvertently deceived by them.

\section{AUTHOR NOTE}

This article was supported by a Swarthmore College faculty research award to F.H.D. We thank Andrew Ward for his suggestions and Don Reynolds for constructing the ramp. Correspondence concerning this article should be addressed to F. H. Durgin, Department of Psychology, Swarthmore College, 500 College Avenue, Swarthmore, PA 19081 (e-mail: fdurgin1@swarthmore.edu).

\section{REFERENCES}

Asch, S. E. (1956). Studies of independence and conformity: I. A minority of one against a unanimous majority. Psychological Monographs, 70, $1-70$.

Balcetis, E., \& Dunning, D. (2007). Cognitive dissonance and the perception of natural environments. Psychological Science, 18, 917-921.

Bhalla, M., \& Proffitt, D. R. (1999). Visual-motor recalibration in geographical slant perception. Journal of Experimental Psychology: Human Perception \& Performance, 25, 1076-1096.

Crabtree, C., Norman, J. F., Bartholomew, A., \& Ferrell, E. (2008). Aging and the perception of slant from optical texture, motion parallax, and binocular disparity [Abstract]. Journal of Vision, 8(6), 859a. doi:10.1167/8.6.859.

Granrud, C. E. (2009). Development of size constancy in children: A test of the metacognitive theory. Attention, Perception, \& Psychophysics, 71, 644-654. doi:10.3758/APP.71.3.644

Hajnal, A., \& Durgin, F. H. (2008). The perception of slope by eye, hand, foot and finger: Evidence for an amodal vertical tendency. [Abstract]. Journal of Vision, 8(76), 76a.

Hutchison, J. J., \& Loomis, J. M. (2006). Does energy expenditure affect the perception of egocentric distance? A failure to replicate Experiment 1 of Proffitt, Stefanucci, Banton, and Epstein (2003). Spanish Journal of Psychology, 9, 332-339.

Loftus, E. F., Miller, D. G., \& Burns, H. J. (1978). Semantic integration of verbal information into a visual memory. Journal of Experimental Psychology: Human Learning \& Memory, 4, 19-31.

Loftus, E. F., \& PALmer, J. P. (1974). Reconstruction of automobile destruction: An example of the interaction between language and memory. Journal of Verbal Learning \& Verbal Behavior, 13, 585-589.

NisbetT, R. E., \& Wilson, T. D. (1977). Telling more than we can know: Verbal reports on mental processes. Psychological Review, 84 , 231-259.

ORNE, M. T. (1962). On the social psychology of the psychological experiment: With particular reference to demand characteristics and their implications. American Psychologist, 17, 776-783.

Proffitt, D. R. (2006). Embodied perception and the economy of action. Perspectives on Psychological Science, 1, 110-122. doi:10.1111/j.1745-6916.2006.00008.x

Proffitt, D. R., Stefanucci, J., Banton, T., \& Epstein, W. (2003). The role of effort in perceiving distance. Psychological Science, 14, 106-112.

Russell, R., \& Durgin, F. H. (2008). Demand characteristics, not effort: The role of backpacks in judging distance [Abstract]. Journal of Vision, 8(6), 755a.

Schachter, S., \& Singer, J. (1962). Cognitive, social, and physiological determinants of emotional state. Psychological Review, 69, 379-399.

Schnall, S., Harber, K. D., Stefanucci, J., \& Proffitt, D. R. (2008). Social support and the perception of geographical slant. Journal of Experimental Social Psychology, 44, 1246-1255.

Stefanucci, J. K., Proffitt, D. R., Clore, G. L., \& Parekh, N (2008). Skating down a steeper slope: Fear influences the perception of geographical slant. Perception, 37, 321-323. doi: 10.1068/p5796.

TVersky, A., \& Kahneman, D. (1974). Judgment under uncertainty: Heuristics and biases. Science, 185, 1124-1131.

WASON, P. C. (1960). On the failure to eliminate hypotheses in a conceptual task. Quarterly Journal of Experimental Psychology, 12, 129-140.

Witt, J. K., Proffitt, D. R., \& Epstein, W. (2004). Perceiving distance: A role of effort and intent. Perception, 33, 570-590. doi:10.1068/ p5090

Woods, A. J., Philbeck, J. W., \& DAnoff, J. V. (2009). The various perceptions of distance: An alternative view of how effort affects distance judgments. Journal of Experimental Psychology: Human Perception \& Performance, 35, 1104-1117. 


\section{ADDENDUM}

"Closing all the doors" refers to a technique in stage magic where the "same" trick is performed more than once, but using a number of different methods, so that all nonmagical explanations seem to be refuted (Macknik et al., 2008). Arguments from converging measures may inadvertently produce the same cognitive illusion. Just because one result is not due to demand characteristics, it does not follow that another is not.

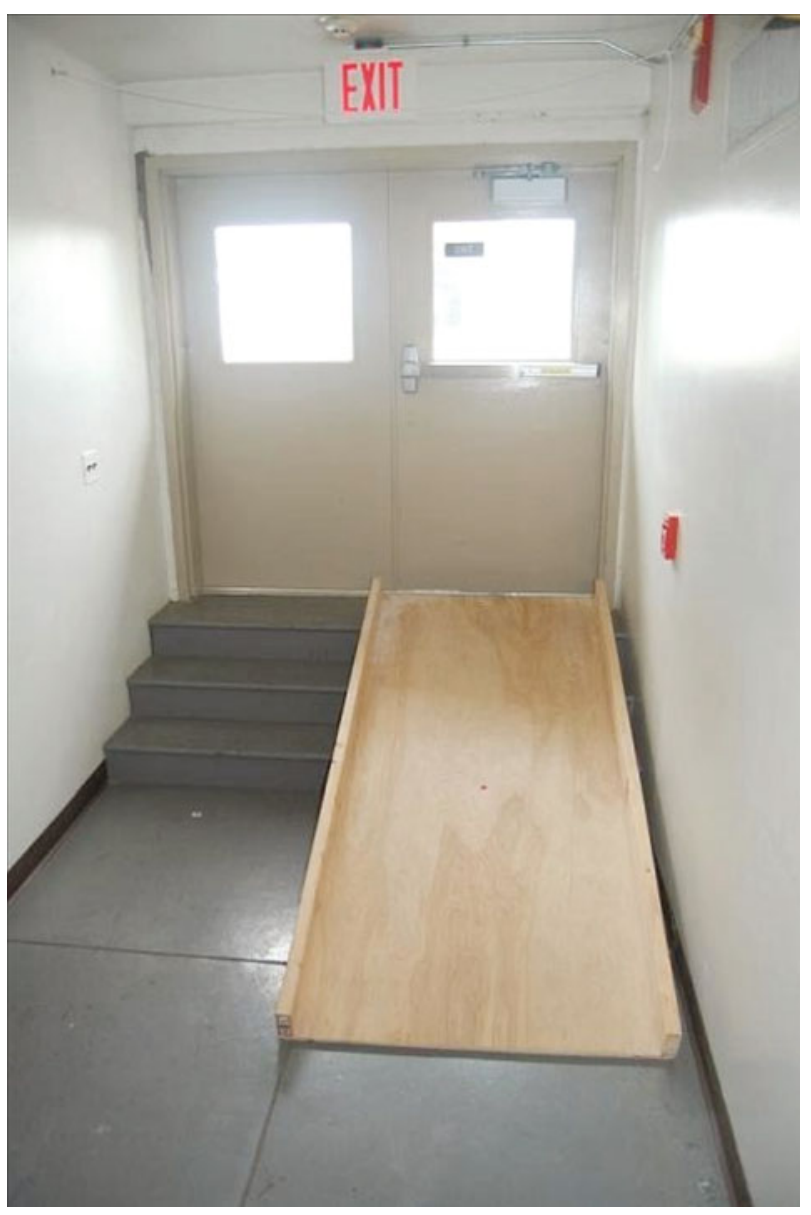

Figure A1. The ramp was constructed of sturdy 19-mm plywood, reinforced with wooden beams to safely afford locomotion. It was mounted on steps, as shown, but surrounded on three sides by black felt curtains to avoid providing any relative orientation information. The rear curtain was made to be irregularly shaped and was bunched at the bottom where it contacted the ramp to avoid the formation of a dihedral angle. Participants initially stood at the base and were asked to look at a dark red fixation mark in the middle of the ramp while making a verbal judgment. They then stepped onto the ramp and made a second verbal judgment based on haptic perception. They could not see the surroundings.
In a reply to our article, Proffitt (2009) argues that our result does not explain his because the physical environments differed. But demand characteristics depend on the social environment, and Schnall, Harber, Stefanucci, and Proffitt (2008) have already shown that backpack effects for large hills can be affected by social factors. We did not "induce" experimental demands. They were obvious to those asked to wear a heavy backpack while making perceptual judgments. They were even inferred by many participants in our elaborate deception condition. Insofar as Proffitt argues that the bioenergetic theory does not apply to ramps, our finding would seem to be a clarifying control: Wearing a backpack produced the same result with our ramp (Figure A1) as with his $5^{\circ}$ hill. ${ }^{1}$

Controlling for demand characteristics is fundamentally important. Effects of demand depend on participants' both perceiving the researcher's intent and cooperating. Several labs, using large outdoor spaces (Hutchison \& Loomis, 2006; Russell \& Durgin, 2008; Woods, Philbeck, \& Danoff, 2009), have failed to replicate backpack effects on distance. Our experiment has documented that most participants guessed the purpose of the backpack, but only some cooperated. This is an important consideration in the design and evaluation of future research.

\section{REFERENCES}

Bhalla, M., \& Proffitt, D. R. (1999). Visual-motor recalibration in geographical slant perception. Journal of Experimental Psychology: Human Perception \& Performance, 25, 1076-1096.

Hutchison, J. J., \& Loomis, J. M. (2006). Does energy expenditure affect the perception of egocentric distance? A failure to replicate Experiment 1 of Proffitt, Stefanucci, Banton, and Epstein (2003). Spanish Journal of Psychology, 9, 332-339.

Macknik, S. L., King, M., Randi, J., Robbins, A., Teller, ThompSON, J., \& MARTINEZ-Conde, S. (2008). Attention and awareness in stage magic: Turning tricks into research. Nature Reviews Neuroscience, 9, 871-879.

ProffitT, D. R. (2009). Affordances matter in geographical slant perception: Reply to Durgin, Baird, Greenburg, Russell, Shaughnessy, and Waymouth. Psychonomic Bulletin \& Review.

Russell, R., \& DuRGIN, F. H. (2008). Demand characteristics, not effort: The role of backpacks in judging distance [Abstract]. Journal of Vision, 8(6), 755a.

Schnall, S., Harber, K. D., Stefanucci, J., \& Proffitt, D. R. (2008). Social support and the perception of geographical slant. Journal of Experimental Social Psychology, 44, 1246-1255.

Woods, A. J., Philbeck, J. W., \& Danoff, J. V. (2009). The various perceptions of distance: An alternative view of how effort affects distance judgments. Journal of Experimental Psychology: Human Perception \& Performance, 35, 1104-1117.

\section{NOTE}

1. Bhalla and Proffitt (1999) had mixed results in their backpack study. Their verbal measure detected a reliable difference only for their $5^{\circ}$ hill. 